\title{
Article \\ Research into the Safe Distance for Opening a Car Door in Order to Avoid Approaching Motorcycles from the Rear
}

\author{
Cheng-Yong Huang
}

Citation: Huang, C.-Y. Research into the Safe Distance for Opening a Car

Door in Order to Avoid Approaching Motorcycles from the Rear. Appl. Sci. 2022, 12, 606. https://doi.org/ 10.3390/app12020606

Academic Editor: Marco Guerrieri

Received: 10 November 2021

Accepted: 6 January 2022

Published: 9 January 2022

Publisher's Note: MDPI stays neutral with regard to jurisdictional claims in published maps and institutional affiliations.

Copyright: (C) 2022 by the author. Licensee MDPI, Basel, Switzerland. This article is an open access article distributed under the terms and conditions of the Creative Commons Attribution (CC BY) license (https:// creativecommons.org/licenses/by/ $4.0 /)$.

\begin{abstract}
Department of Arts and Design, National Dong Hwa University, Hualien 974301, Taiwan; yong@gms.ndhu.edu.tw
\end{abstract}

\begin{abstract}
Car drivers may misjudge the speed and distance of oncoming vehicles when getting out of their vehicles, leading to door crash accidents. The author invented a patented side-view mirror with distance markers to prevent such door crash accidents. Through the means of behavioural observation experiments, the main objective of this research was to observe the minimum safe distance from the rear of an approaching vehicle when opening the door of the car. The experimental results determined that the use of the Dutch Reach method yielded the shortest safe distance. Compared to the other three judgment solutions, the use of the patented side-view mirror with a distance marker to judge the minimum average safety distance had the longest distance and was the safest, meaning that it is able to help female drivers to judge the distance of approaching motorcycles from the rear and to maintain a sufficient safe distance when opening the door.
\end{abstract}

Keywords: behavioural observation; vehicle door crash; safe distance; Dutch Reach; side-view mirror

\section{Introduction}

Taiwan has a population of approximately 23.45 million people, and a population density of 648 people per square kilometre, ranking as the 10th most densely populated region in the world. In terms of traffic patterns, Taiwan has the highest ratio of motorcycles to other road vehicles in the world [1]. As of August 2021, Taiwan had a total of 22.48 million powered vehicles, of which 8.28 million were cars and 14.2 million were motorcycles. The number of motorcycles was almost 1.72 times that of automobiles. Motorcycles usually drive in the outer lanes of roads. For the convenience of car drivers, car parking lots are usually drawn on the outer side of the road. With Taiwanese motorcyclists usually driving next to car parking lots by the roadside, accidents in which car drivers improperly open the doors of their cars, causing the motorcycle behind the car to dodge the door, resulting in injuries, happen with great frequency.

Car drivers rely on vision to judge the speed and distance of an approaching vehicle, but due to the small surface area of the motorcycle, wrong speed and distance judgments may be made, thus causing car accidents [2].

When getting out of a car, drivers will often use their side-view mirror to see whether or not there is a vehicle approaching from the rear. They will only open the door after confirming that there is no approaching vehicle. The design of a side-view mirror is often simply a mirror. The relevant literature has discussed the use of a convex side-view mirror that increases the driver's field of vision, but they tend to overestimate the distance between the driver and the vehicle behind them. Hence, convex side-view mirrors are banned in the United States [3]. However, there are some side-view mirrors that have a warning printed on them that says "Warning! Objects in the mirror are closer than they appear" [4]. Hahnel and Hecht carried out a study on how the distance and curvature of a side-view mirror impacts road safety-related judgements. They found that variations in mirror distance had a significant effect on time-to-contact (TTC) judgements but that they only marginally influenced distance and spacing estimations. As mirror distance increased, the TTC was 
overestimated, which is potentially dangerous [5]. Thus, it is important that the driver is able to correctly judge the distance of the vehicle approaching from the rear when using a side-view mirror. The author has invented a side-view mirror with a distance marker and will verify its effectiveness with this research. In order to avoid door crash accidents caused by driver's misjudging speed and distance, this research conducted a minimum safe distance behavioural observation experiment where a car door was opened when vehicles were approaching from behind. The main purpose and results of this research will be the use of the results as the criterion for judging the safe protection distance when drivers open the doors of smart cars in the future.

\section{Literature Survey}

\subsection{Door Crash Accidents}

In Western countries, more commuters ride bicycles and there are fewer motorcycles. The earliest mention of door crash accidents can be found in a study conducted by Dennerlein and Meeker [6]. The vehicle door crash mentioned in the study refers to the injuries sustained from two collision points, the first time point being when the cyclist collides with the door, and the second time point being when the cyclist makes contact with the ground, especially the cyclist is not wearing a helmet.

Pei's research [7] mentioned that most bicycle lanes are placed in areas that parked cars open their doors into, that is, the car doors extend about $90-105 \mathrm{~cm}$, and the bicycle lanes are usually only slightly wider than $90-105 \mathrm{~cm}$. This undoubtedly increases the risk of cyclists crashing into car doors. The study found that apart from bicycle lanes being close to the car parking lots, taxis frequently let passengers embark on and exit the car there, and female cyclists and female car drivers are also prone to door crash accidents involving bicycles. Additionally, it was found that one-way roads, older cyclists, and daytime are factors that may lead to being more prone to door crash accidents. Despite the fact that bicycles usually travel in the center of a bicycle lane, cyclists are usually instructed to ride one door away from vehicles parked on the side of the road, which can increase the visibility of the cyclist as well as the vision of the car driver. Johnson, Newstead, Oxley, and Charlton [8] conducted a study on bicycle door crash accidents and found that male cyclists, those 18-years-old and above, and roads with a speed limit of 60 and above are factors that would lead one to be more prone to door crash accidents involving bicycles.

Due to the different traffic patterns in Taiwan, unlike other countries, there are very few door crash accidents involving cars and bicycles. On the contrary, door crash accidents involving cars and motorcycles resulting in severe injuries are far more prevalent. Chen, Wang, Linlov, and Pai's research [9] collected vehicle door crash data in Taipei City and used the results of a mixture of multiple logit models to present the results that random parking, elderly car passengers, young car passengers, drunk car passengers and motorcyclists, and speeding motorcycles are the main causes of vehicle door crashes. A vehicle door crash on the rear left side has a significant relationship with female passengers and taxis. Huang's [10] research found that winter, daytime, morning, male motorcyclists, heavy motorcycles, and the left side of the car are risk factors that are likely to cause door crash accidents that result in severe casualties. Regarding the gender differences seen in motorcyclists, it has been found that female motorcyclists have a higher proportion of accidents involving improper door opening, while male motorcyclists are 1.658 times more likely than female motorcyclists to suffer serious injuries and death after accidents.

\subsection{Safe Distance and Dutch Reach}

Generally, the idea of safe distance in cars refers to the distance that should be maintained from another vehicle in front of you whilst moving [11]. The current research in this area is mainly applied to the car-following function of Advanced Driver Assistance Systems (ADAS), such as [12-14]. Pei [7] mentioned that regardless of whether a bicycle is being ridden in the bicycle lane or not, the cyclist should maintain a distance of more than one door from the roadside car when riding. This can also increase the visibility of 
the cyclist as well as that of the driver of a car parked on the side of the road when getting out of the car. In this study, the safe door opening distance refers to the distance of the motorcycle behind the car at which the driver of the car will not open the door. This is very similar to the safe distance from the car, which is the car driver's psychological evaluation of a safe distance to ensure that the opening of the door will not hit the motorcycle coming from the rear.

Moreover, in order to ensure that the car driver can turn around to determine whether there is a car coming from behind, the Dutch Reach method has been proposed as a potential solution. It is recommended that drivers use their "far hand" (i.e., the hand furthest from the door) to operate the door handle. It is expected that this will change the driver's posture as a result, particularly their head orientation. Consequently, they can better see the sides and rear of the vehicle and can thus more easily detect approaching danger. Studies have found that using Dutch Reach to open the door increases head rotation, and it has also been found that car drivers use Dutch Reach to open the door when they are specifically asked to open the door in a way that increases their awareness of the danger of an approaching vehicle from behind [15].

\section{Experimental Design}

In order to avoid door crash accidents, Huang [16] discovered that car drivers can act in four different ways when opening the car door. The first way is to directly open the door and get out of the car. The second way is to observe oncoming vehicles through the side-view mirror before opening the door. The third way is to first only partially open the door, probe their head out to observe oncoming vehicles, and then open the door after confirming that there is no car (Dutch Reach). The fourth way is to turn around and observe the oncoming traffic from the rear left window. More than half of drivers observe approaching vehicles from the side-view mirror. The main purpose of this research is to avoid door crash accidents and to conduct a behavioural observation experiment of the minimum safe distance needed to open a car door. The study focuses on the judgment of test subjects in determining the minimum safe distance from a car coming from behind. In order to achieve the purpose of this study, in addition to traditional side-view mirrors, patented side-view mirrors with distance markings were incorporated to conduct behaviour observation experiments in order to determine the optimum safe distance at which a driver can open the door. The patented side-view mirrors with distance markings are shown in Figure 1 [17].

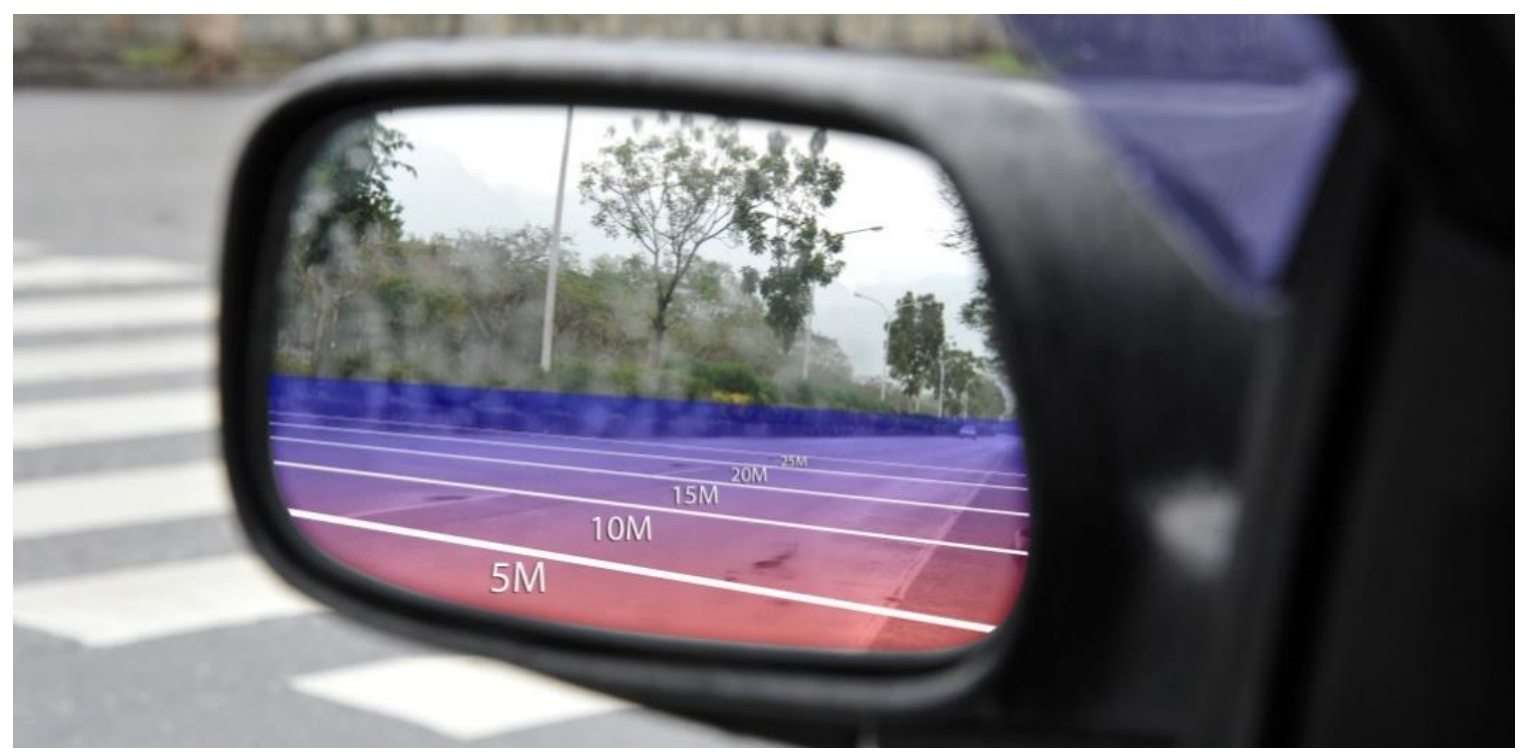

Figure 1. Patented side-view mirror with distance markings. 
This study seeks test subjects who are over 20 years old and who have a car driver's license. Their basic personal data including gender, age, driving experience, and major modes of transportation will first be recorded. Next, the experiment assistant will briefly explain the experiment process and content to the test subject, and the participant will then enter the test vehicle. Four solutions will be judged to the determine the minimum safe distance from behind. The vehicle used for the experiment was a 2300 cc Ford Escape SUV. The experiment took place in the daytime, between 2-4 pm. For the sake of experimental safety, the vehicle was parked on a university campus road where there were fewer vehicles and people. A shady place was chosen to prevent sunlight from affecting the subjects. Each subject needed about 20 min to complete the experiment, and 4-5 people were arranged to complete the experiment each day. The entire experiment took around 10 days. The environment that was used for the experiment is as shown in Figure 2.

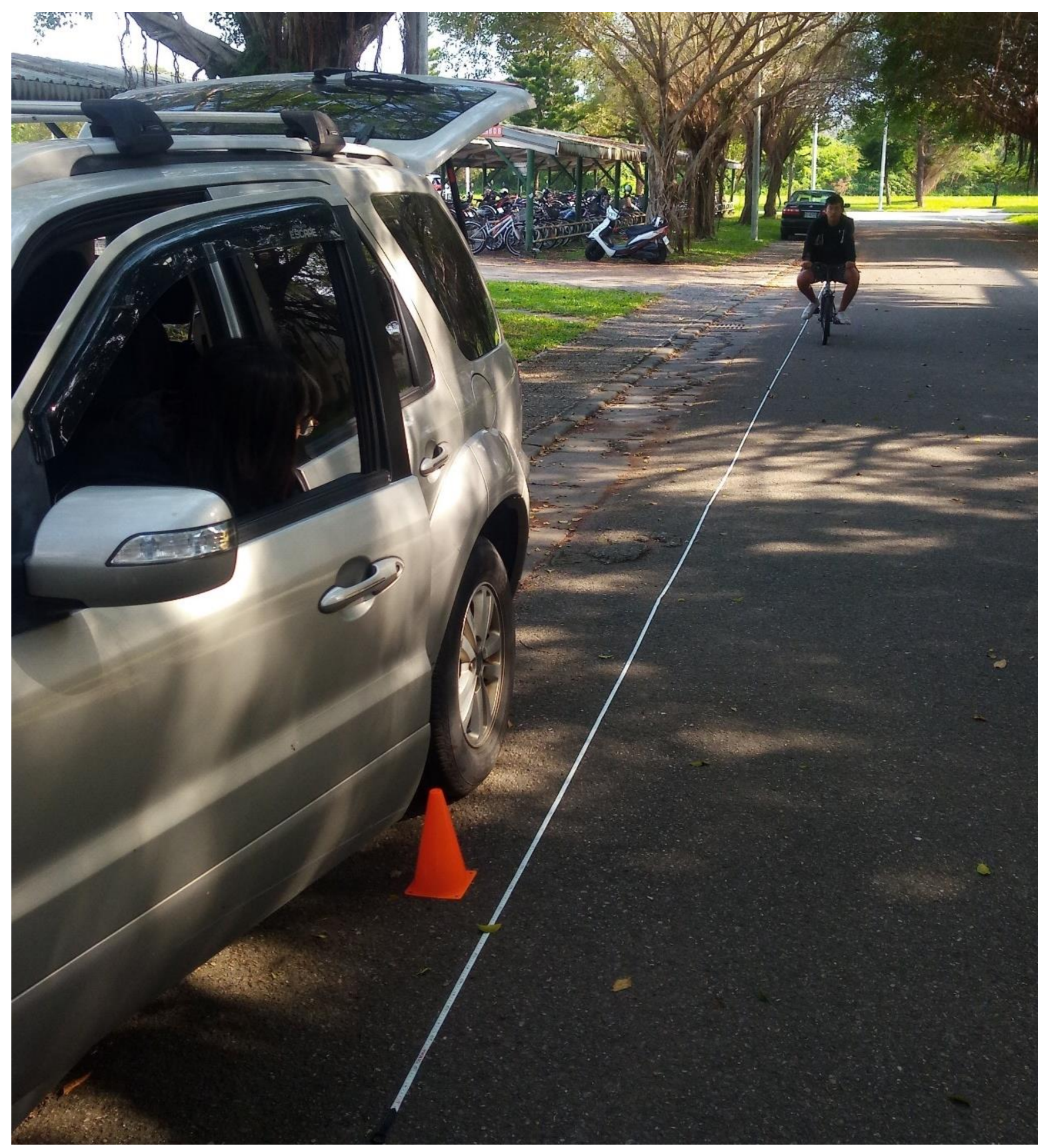

Figure 2. Experiment environment. 
The first part of the experiment was the general judgment made by the driver when using a side-view mirror. The Standard Operation Procedure (SOP) of the experiment is as follows: After the test subject gets into the vehicle, 1. they will adjust the seat to a comfortable position and will adjust the angle of the backrest. 2 . The test subject will then turn on the car engine. 3. The test subject will adjust the angle of the side-view mirror. 4. After the test subject has confirmed that the seat and the side-view mirror have been properly adjusted, the shortest safe distance experiment begins. 5 . The experiment assistant will approach the experiment vehicle on a bicycle at a speed of $10-20 \mathrm{~km}$ from $50 \mathrm{~m}$ behind. 6. During the test the test subject informs the experiment assistant to stop the bicycle after reaching the minimum safe distance. 7 . The minimum safe distance is then measured.

The second part of the experiment uses the patented side-view mirror. The distance marker image is transferred onto a $1 \mathrm{~mm}$ thick piece of a transparent acrylic sheet. The shape of the acrylic sheet is the same as that of the side-view mirror. The SOP of the experiment is as follows: 1 . The experiment assistant fixes the acrylic sheet with distance marker onto the side-view mirror. 2. The test subject turns on the car engine. 3 . The test subject adjusts the angle of the side-view mirror so that the horizontal line in the real environment matches the horizontal line of the distance marker. This is to ensure the accuracy of the rear distance detection. Steps 4, 5, 6 and 7 are the same as the first part of the experiment.

The third part of the experiment judges the minimum safe distance using the Dutch Reach method, where the driver opens the door and then turns to look behind them. The SOP of the experiment is the same as steps $4,5,6$, and 7 of the previous experiments. The fourth part of the experiment has the test subject stand directly outside the door, and then steps 4, 5, 6, and 7 from the previous experiments are repeated. Every test subject underwent the above four parts of the experiment three times, and the experiment took approximately 20 minutes in total. The data obtained from the experiment were then used to conduct the statistical analysis of ANOVA.

\section{Experimental Results}

A total of 51 subjects were recruited for this experiment, 34 males and 17 females. All of them were aged between 20-65 years old, with their driving experience ranged from 1 to 20 years with educational levels being at the university and research institute level. A total of 31 of them used cars as their main means of transportation. The four methods for judging the minimum safe distance for these 51 subjects (A1: general side-view mirror, A2: patented side-view mirror with distance marking, A3: Dutch Reach, and A4: stands outside the vehicle door) were used for the minimum safe distance behavioural observation experiment, and statistical analysis was carried out. The descriptive statistics are shown in Table 1.

Table 1. Descriptive statistics of the four solutions.

\begin{tabular}{ccccc}
\hline Solutions & General & Patent & Dutch Reach & Outside \\
\hline Mean & $14.2379 \mathrm{~m}$ & $15.0399 \mathrm{~m}$ & $12.9732 \mathrm{~m}$ & $13.9586 \mathrm{~m}$ \\
Standard Error & 0.33941 & 0.31411 & 0.35922 & 0.3698 \\
Median & $13.8 \mathrm{~m}$ & $15 \mathrm{~m}$ & $13 \mathrm{~m}$ & $12.9 \mathrm{~m}$ \\
Standard Deviation & 4.19831 & 3.88534 & 4.44327 & 3.9487 \\
Variance & 17.626 & 15.096 & 19.743 & 15.592 \\
Kurtosis & 0.542 & -0.093 & -0.231 & -0.261 \\
Skewness & 0.698 & 0.124 & 0.395 & 0.409 \\
Range & 21.50 & 18.30 & 20.80 & 17.30 \\
Minimum & $6.50 \mathrm{~m}$ & $6.00 \mathrm{~m}$ & $5.10 \mathrm{~m}$ & $6.20 \mathrm{~m}$ \\
Maximum & $28.00 \mathrm{~m}$ & $24.30 \mathrm{~m}$ & $25.90 \mathrm{~m}$ & $23.50 \mathrm{~m}$ \\
Sum & $2178.40 \mathrm{~m}$ & $2301.10 \mathrm{~m}$ & $1984.90 \mathrm{~m}$ & $1533.90 \mathrm{~m}$ \\
Count & 153 & 153 & 153 & 114
\end{tabular}




\subsection{Statistical Analysis}

ANOVA analysis is mainly used to compare the variation in the means of different groups. It is often used in vehicle behavioural observation experiments, such as in [18-20]. The results of the ANOVA analysis produce an F value, which shows the variation within a group and between groups. If sig. $<0.05$, then there is a statistically significant differences between the results. This piece of research uses ANOVA to compare 1 . if there is a statistically significant differences between the minimum safe distances of the four solutions; 2. to determine whether there is a statistically significant difference among males with regard to the minimum safe distance determined by the four solutions; 3 . whether there is a statistically significant difference among females with regard to the minimum safe distance determined by the four solutions; and 4. whether there is a relationship between gender and the four different solutions. The first three use one-way ANOVA analysis, and the last one uses two-way ANOVA analysis. The statistical results of the data using SPSS 19 are shown later.

\subsection{One-Way ANOVA Analysis of the Solutions}

The 51 test subjects used the four methods to open the car door and to pay attention to the minimum safe distance from the motorcycle coming from behind. The test was repeated three times before performing the one-way ANOVA analysis of the solutions. The statistical results are shown in Table 2. It turns out that the average shortest safe distance is Dutch Reach, at $12.97 \mathrm{~m}$, and the longest is when using the patented side-view mirror, at $15.04 \mathrm{~m}$. There is a significant difference in the one-way analysis of variance results. After comparison, it was found that the average safe distance when using a general side-view mirror was greater than that of Dutch Reach, which presents a significant difference, while the average safe distance of the patented side-view mirror is greater than that of Dutch Reach and standing outside the car door. The statistics of the distance averages show substantial distinction. Safety comparison: Patent $>$ General $>$ Outside $>$ Dutch Reach.

Table 2. One-Way ANOVA analysis of the solutions.

\begin{tabular}{ccccccc}
\hline Solutions & N & Mean & SD & F & Sig. & Post Hoc Test \\
\hline General & 153 & $14.24 \mathrm{~m}$ & 4.20 & & & General $>$ Dutch * \\
Patent & 153 & $15.04 \mathrm{~m}$ & 3.89 & & & \\
Dutch Reach & 153 & $12.97 \mathrm{~m}$ & 4.44 & 7.174 & $0.000 *$ & Patent $>$ Dutch * \\
Outside & 114 & $13.45 \mathrm{~m}$ & 3.95 & & & Patent $>$ Outside * \\
\hline * indicates a 0.05 significance level.
\end{tabular}

\subsection{One-Way ANOVA Analysis of the Male Solutions Data}

The male data were retrieved to perform a one-way analysis of variance of the solutions. The statistical results are shown in Table 3. The results show that the shortest safe distance average is $13.84 \mathrm{~m}$ for Dutch Reach, and the longest is $15.64 \mathrm{~m}$ for the patented side-view mirror. There is a significant difference in the statistical analysis results for the one-way analysis of variance. After the comparison, it was found that the average safe distance when using the general side-view mirror is greater than that of Dutch Reach and the safe distance when opening the door and standing outside, which presents a statistically significant difference. The average safe distance determined by the patented side-view mirrors is greater than the average safe distance determined by Dutch Reach and by opening the door and standing outside, which shows great statistical significance. Safety comparison: Patent $>$ General $>$ Outside $>$ Dutch Reach 
Table 3. One-Way ANOVA analysis of male solutions data.

\begin{tabular}{ccccccc}
\hline Solutions & N & Mean & SD & F & Sig. & Post Hoc Test \\
\hline General & 102 & $15.14 \mathrm{~m}$ & 4.31 & & & General $>$ Dutch * \\
Patent & 102 & $15.64 \mathrm{~m}$ & 4.17 & \multirow{2}{*}{5.698} & \multirow{2}{*}{$0.001 *$} & General $>$ Outside * \\
Dutch Reach & 102 & $13.84 \mathrm{~m}$ & 4.58 & & & Patent $>$ Dutch * \\
Outside & 81 & $13.44 \mathrm{~m}$ & 3.82 & & & Patent $>$ Outside * \\
\hline
\end{tabular}

*. The mean difference is significant at the 0.05 level.

\subsection{One-Way ANOVA Analysis of the Female Solutions Data}

The female data were retrieved to perform a one-way analysis of variance of the solutions. The statistical results are shown in Table 4 . The results show that the shortest safe distance average is $11.25 \mathrm{~m}$ for Dutch Reach, and the longest is $13.84 \mathrm{~m}$ for the patented side-view mirror. There is a significant difference in the one-way analysis of variance. After the comparison, it was found that the average safe distance of the patented side-view mirror is greater than that of the general side-view mirror and Dutch Reach, which presents a statistically significant difference. The average safe distance of opening the door and standing outside is greater than the average safe distance using Dutch Reach, which shows great statistical significance. Safety comparison: Patent $>$ Outside $>$ General $>$ Dutch Reach

Table 4. One-Way ANOVA analysis of female solutions data.

\begin{tabular}{|c|c|c|c|c|c|c|}
\hline Solutions & $\mathbf{N}$ & Mean & SD & $\mathbf{F}$ & Sig. & Post Hoc Test \\
\hline General & 51 & $12.44 \mathrm{~m}$ & 3.32 & \multirow{4}{*}{5.424} & \multirow{4}{*}{0.001 * } & \multirow{4}{*}{$\begin{array}{l}\text { Patent }>\text { General * } \\
\text { Patent }>\text { Dutch * } \\
\text { Outside }>\text { Dutch * }\end{array}$} \\
\hline Patent & 51 & $13.84 \mathrm{~m}$ & 2.92 & & & \\
\hline Dutch Reach & 51 & $11.25 \mathrm{~m}$ & 3.62 & & & \\
\hline Outside & 33 & $13.51 \mathrm{~m}$ & 4.31 & & & \\
\hline
\end{tabular}

*. The mean difference is significant at the 0.05 level.

\subsection{Two-Way ANOVA Analysis of Gender and Solutions}

The results of the two-way variance analysis of gender and solutions found that gender and solutions have a statistically significant difference, and gender and solutions have an interactive effect, as shown in Table 5. However, in terms of looking at the safe distance solutions from the perspective of different genders, as shown in Figure 3, women tend to have a shorter safe distance than men, so they are more likely to experience accidents when opening the car door. However, there is little difference in the results from the male participants in terms of opening the door and judging the safe distance from outside of the car.

Table 5. Two-way ANOVA analysis of gender and solutions.

\begin{tabular}{cccccc}
\hline Source & Type III Sum of Squares & df & Mean Square & F & Sig. \\
\hline Corrected Model & $955.337^{\text {a }}$ & 7 & 136.477 & 8.428 & $0.000^{*}$ \\
Intercept & $90,904.804$ & 1 & $90,904.804$ & 5613.595 & $0.000^{*}$ \\
Gender & 376.801 & 1 & 376.801 & 23.268 & $0.000^{*}$ \\
Solutions & 334.440 & 3 & 111.480 & 6.884 & $0.000^{*}$ \\
Gender Solutions & 129.740 & 3 & 43.247 & 2.671 & $0.047^{*}$ \\
Error & 9149.433 & 565 & 16.194 & & \\
Total & $121,750.150$ & 573 & & & \\
Corrected Total & $10,104.770$ & 572 & & & \\
\hline
\end{tabular}

*. The mean difference is significant at the 0.05 level. 


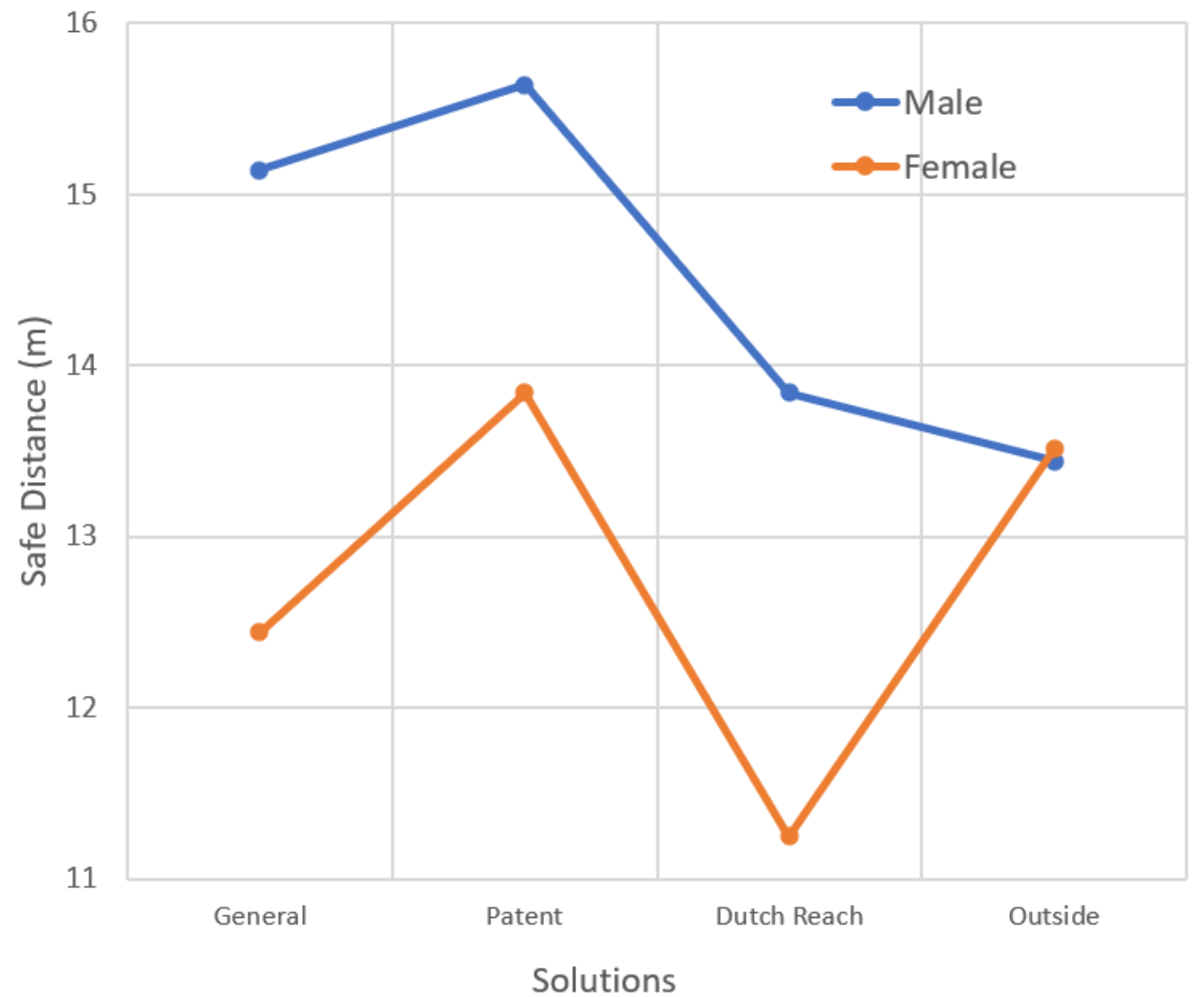

Figure 3. Gender differences in the safe distance chart of solutions.

\section{Discussion}

As we can see from the results of the one-way analysis of variance statistics, the safe distances of the four solutions show significant differences. The longest average safe distance maintained by using the patented side-view mirror is $15.04 \mathrm{~m}$, while the distance between Dutch Reach and standing outside the door and judging with the naked eye is relatively short, being 12.97 and $13.53 \mathrm{~m}$, respectively. However, there are differences among different genders when judging the average safe distance among the different solutions. From the results of the two-way analysis of variance in Table 5, it is clear that the F value for gender is 24.961, and Sig. $<0.05$ is a significant difference. Spatial ability refers to the cognitive process involved in locating a target in space, perceiving the relationship between distance and direction, as well as the process of psychologically changing the position or direction of an object in space. Spatial ability is of interest to gender researchers because it is an area where there is the most obvious evidence for differences in cognition [21]. This research has discovered that in terms of judging distance, there are significant differences among different genders.

Therefore, males and females were separated for one-way analysis of variance. According to the data for males, the average safe distance between the patented and the general side-view mirror is greater than $15 \mathrm{~m}$. This is significantly different to the average value of the safe distance maintained by turning the head around to use Dutch Reach and by standing outside the door and observing with the naked eye. The statistical results of the data from females are different to the statistical results obtained from the male participants. The average safe door opening distance was the longest when the patented side-view mirrors were used, but there is not much difference in the average safe distance when judging with the naked eye from outside the car door. However, there is a noticeable difference from when general side-view mirrors as well as when the Dutch Reach solutions are. Therefore, it was determined that the patented side-view mirror is better than the general side-view mirror in helping female drivers to judge the distance of motorcycles coming from behind. On the other hand, there is a statistical difference between using 
Dutch Reach to turn around and look behind, which maintains a shorter door opening safe distance, and standing outside the door to determine the safe distance of oncoming motorcycles. This may be due to the differences in the perceptions of rear distance when sitting and standing. Related research also shows that women have a larger gap when perceiving spatial distance than men [22,23].

According to the statistical results of the two-way analysis of variance of gender and solutions, it was found that the safe distances for opening doors maintained by women using a patented side-view mirror, general side-view mirror, and Dutch Reach are shorter than those maintained by men. The only aspect that is the same as men is the safe distance needed when opening the door and judging from the outside. This safe distance is also close in value to the safe distance that women maintain when using the patented side-view mirror, which proves that the patented side-view mirror will help female drivers in distance perception when determining the distance of approaching motorcycles. In recent years, the automobile industry has achieved rapid advancements in autonomous vehicles and advanced driver-assistance system (ADAS) technologies. One of the technologies related to distance detection is the parking assistance system [24]. The patented side-view mirror can also be combined with vision-based parking assistance systems (VPAS) to provide female or elderly drivers with more accurate visual information for parking or reversing.

Finally, judging from the cumulative percentage chart of each solution, as shown in Figure 4, it can also be found that the Dutch Reach method for opening of the car door and turning around to judge the safe distance of the approaching motorcycle is shorter (to the left), followed by standing outside the car door to determine the safe distance. The difference between the two should be related to height at eye level, hence using the outside solution should be more accurate than using the Dutch Reach solution. Gender differences can be seen in this regard. There is not much difference between males and females when using the outside solution, but the obvious safe distance determined by females using the Dutch Reach solution is about $2 \mathrm{~m}$ shorter than that of males. The use of patented side-view mirrors also demonstrates gender differences, but the patented side-view mirror has the longest distance compared to other solutions, which can effectively allow drivers to maintain a sufficient safe distance, especially for female drivers. The use of patented side-view mirrors also demonstrates gender differences, but the patented side-view mirror has the longest distance compared to other solutions, which can effectively allow drivers to maintain a sufficiently safe distance, especially female drivers. The results from this section were used to develop a vehicle door opening control model based on fuzzy inference system to prevent motorcycle-vehicle door crashes. From the cumulative percentage chart, when the test subjects used the Dutch Reach method, the safe distance was as short as $5 \mathrm{~m}$ and as long as $25 \mathrm{~m}$, with a mean of $13 \mathrm{~m}$ and a standard deviation of $4.4 \mathrm{~m}$. The membership function of the safe distance covers a range set between $0-25 \mathrm{~m}$. The medium function of the safe distance is set as the mean plus or minus the standard deviation, and the range is approximately between 9-17 $\mathrm{m}$. The whole membership function has five levels ranging from very close to very far away [25]. 


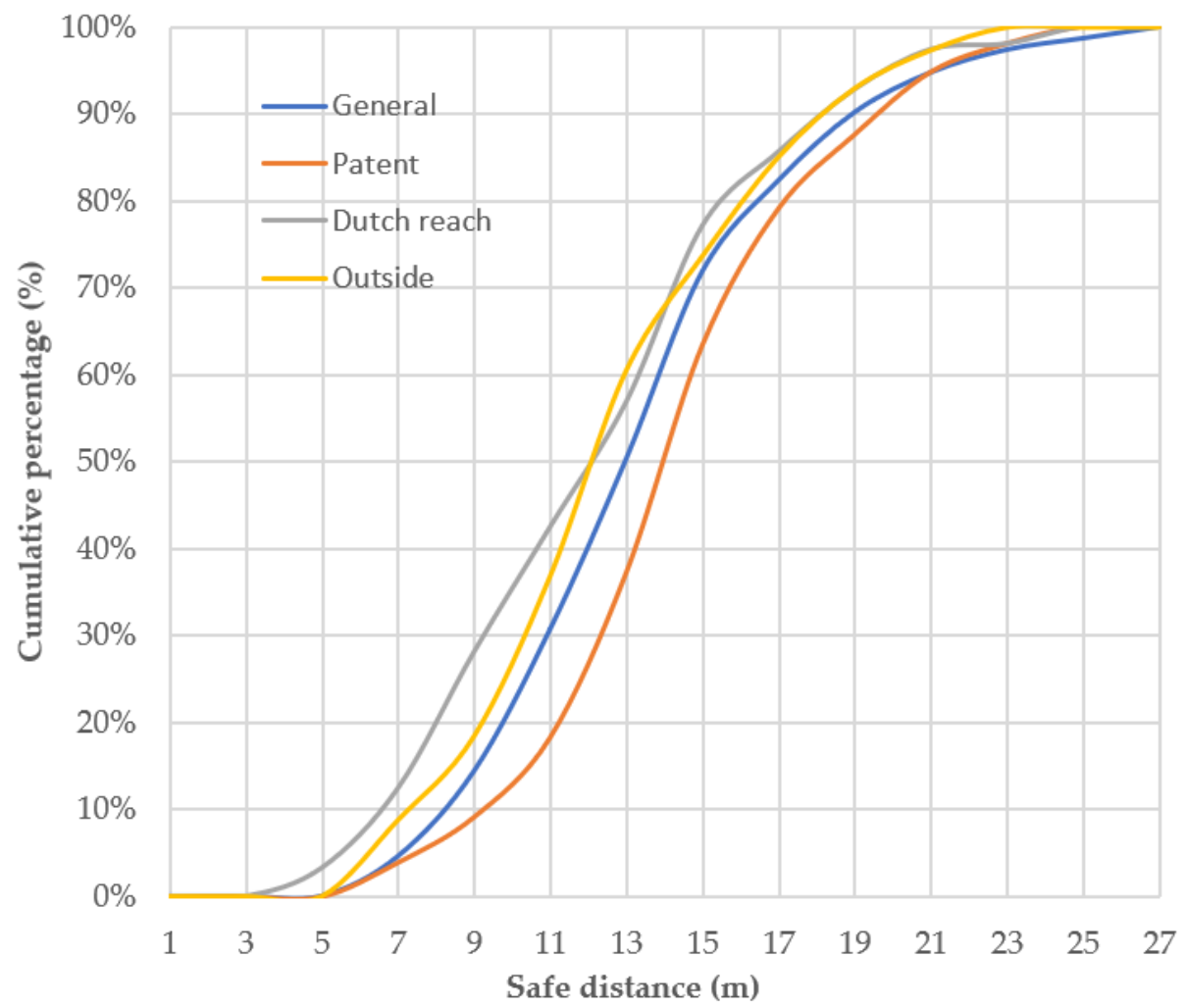

Figure 4. Cumulative percentage chart of each solution.

\section{Conclusions}

The unique traffic patterns of Taiwan have led to a high frequency of door crash accidents. The author invented a patented side-view mirror with distance markings to solve the problem of judging the distance of oncoming vehicles. A behavioural observation experiment determining the minimum safe distance was conducted in this study, where four solutions for judging the distance of a vehicle coming from the rear were evaluated, and it was found that the safe distance from the rear motorcycle was the shortest when using the Dutch Reach method. Compared to the other three judgment solutions, the use of a patented side-view mirror with a distance marker to judge the minimum safe distance has the longest safe distance and is the safest solution, which can effectively allow the driver to maintain a sufficiently safe distance when opening the car door. The safe distance determined by different solutions differs by gender, and the patented side-view mirror will help female drivers maintain a sufficient safe distance when opening the car door.

There are potential research limitations to this study. In terms of the test subjects, the proportion of male test subjects was twice that of female subjects. Even though this is in line with the gender ratio of Taiwanese car drivers, in terms of the statistics, it presents the problem of statistical homogeneity. In addition, the driving experience of the test subjects differed, giving rise to differences. In terms of the test vehicle used, an SUV with a higher chassis was used, so the eye level and the seat level were different to that of a regular car. With general side-view mirrors, the vehicle's original side-view mirror would be used. The patented distance marker was printed onto a $1 \mathrm{~mm}$ thick sheet of acrylic and affixed onto the vehicle's original side-view mirror and did not take the different curvatures of different side-view mirrors, such as whether a mirror is more concave or convex, into consideration. In terms of the sample size, this research is considered a pilot study. There were only 51 test subjects, and each test subject underwent the experiment three times; hence $n=153$ results were obtained, roughly meeting the minimum sample requirements for ANOVA. In terms of the test environment, in order to protect the safety of the test subjects, the experiment took place on a quiet road within a university campus with fewer people and vehicles. In 
order to avoid the sunlight affecting the test subjects' distance judgement, the experiment took place in a shady area. This would all be different in real-world driving conditions.

The research results of this experiment will be used as a reference for the future design and development of side-view mirrors with distance markers as well as for the judgment standard for the safe protection distance of the driver when opening the doors of smart cars in the future.

At present, the preliminary research results for this experiment have been applied towards creating a vehicle door opening control model based on a fuzzy inference system to prevent motorcycle-vehicle door crashes [25]. In the future, side-view mirror with distance marker will be further applied to side-view mirrors with different curvatures as well as for different types of vehicles in order to judge the effectiveness of the driver in judging distance. In addition, it will be used in digital side-view mirrors to help drivers judge the distance when changing lanes and to assist them when getting out of a car. Furthermore, we will make a small-scale mass request for drivers to use the patented side-view mirror in real road conditions to test its usability and to undergo human behavioural observation testing. Lastly, further human engineering behavioural observation experiments will be carried out for the dynamic distance measurements of oncoming vehicles from the rear.

Funding: Research was funded by Ministry of Science and Technology (MOST), Taiwan, R.O.C. under grant number MOST 107-2221-E-259-015-.

Institutional Review Board Statement: The protocol (NTU-REC No.: 201806ES076) has been approved by the Research Ethics Committee of National Taiwan University and has been classified as expedited on 26 September 2018. The committee is organized under, and operates in accordance with, Social and Behavioral Research Ethical Principles and Regulations of National Taiwan University and governmental laws and regulations.

Informed Consent Statement: Informed consent was obtained from all subjects involved in the study.

Data Availability Statement: Provided by the author upon request.

Conflicts of Interest: The author declare no conflict of interest.

\section{References}

1. Pai, C.-W.; Hsu, J.-J.; Chang, J.-L.; Kuo, M.-S. Motorcyclists violating hook-turn area at intersections in Taiwan: An observational study. Accid. Anal. Prev. 2013, 59, 1-8. [CrossRef]

2. Hjelkrem, O.A.; Ryeng, E.O. Chosen risk level during car-following in adverse weather conditions. Accid. Anal. Prev. 2016, 95, 227-235. [CrossRef] [PubMed]

3. Flannagan, M.J.; Sivak, M.; Schumann, J.; Kojima, S.; Traube, E.C. Distance Perception in Driver-Side and Passenger-Side Convex Rearview Mirrors: Objects in Mirror Are More Complicated Than They Appear; University of Michigan Transportation Research Institute: Ann Arbor, MI, USA, 1997.

4. Libertun, A.R. Warning! Objects in mirror are closer than they appear. Phys. Teach. 2003, 41, 20-21. [CrossRef]

5. Hahnel, U.J.J.; Hecht, H. The impact of rear-view mirror distance and curvature on judgements relevant to road safety. Ergonomics 2012, 55, 23-36. [CrossRef] [PubMed]

6. Dennerlein, J.T.; Meeker, J.D. Occupational injuries among Boston bicycle messengers. Am. J. Ind. Med. 2002, 42, 519-525. [CrossRef] [PubMed]

7. Pai, C.-W. Overtaking, rear-end, and door crashes involving bicycles: An empirical investigation. Accid. Anal. Prev. 2011, 43, 1228-1235. [CrossRef]

8. Johnson, M.; Newstead, S.; Oxley, J.; Charlton, J. Cyclists and open vehicle doors: Crash characteristics and risk factors. Saf. Sci. 2013, 59, 135-140. [CrossRef]

9. Chen, P.-L.; Wang, M.-H.; Linkov, V.; Pai, C.-W. Motorcycle door crashes: An evaluation of crash characteristics in Taipei City, Taiwan. PLoS ONE 2018, 13, e0208016. [CrossRef] [PubMed]

10. Huang, C.-Y. Risk Factors Analysis of Car Door Crashes Based on Logistic Regression. Sustainability 2021, 13, 10423. [CrossRef]

11. Adell, E.; Várhelyi, A.; Fontana, M.d. The effects of a driver assistance system for safe speed and safe distance-A real-life field study. Transp. Res. Part C Emerg. Technol. 2011, 19, 145-155. [CrossRef]

12. Yimer, T.H.; Wen, C.; Yu, X.; Jiang, C. A study of the minimum safe distance between human driven and driverless cars using safe distance model. arXiv 2020, arXiv:2006.07022.

13. Adell, E.; Varhelyi, A.; Alonso, M.; Plaza, J. Developing human-machine interaction components for a driver assistance system for safe speed and safe distance. IET Intell. Transp. Syst. 2008, 2, 1-14. [CrossRef] 
14. Bertolazzi, E.; Biral, F.; Lio, M.D.; Saroldi, A.; Tango, F. Supporting Drivers in Keeping Safe Speed and Safe Distance: The SASPENCE Subproject Within the European Framework Programme 6 Integrating Project PReVENT. IEEE Trans. Intell. Transp. Syst. 2010, 11, 525-538. [CrossRef]

15. Large, D.; Choo, M.; Houghton, R. Validating 'Dutch Reach': A Preliminary Evaluation of Far-Hand Door Opening and Its Impact on Car Drivers' Head Movements. In Proceedings of the 7th International Cycling Safety Conference, ICSC2018, Barcelona, Spain, 10-11 October 2018.

16. Huang, C.-Y. Observations of Drivers' Behavior when Opening Car Doors. Procedia Manuf. 2015, 3, 2753-2760. [CrossRef]

17. Huang, C.-Y. Distance Estimation Marker Structure for a Vehicle Side-View Mirror. TIPO Utility Model Patent M504030, 1 January 2015.

18. Pérez-Zuriaga, A.M.; Moll, S.; López, G.; García, A. Driver Behavior When Overtaking Cyclists Riding in Different Group Configurations on Two-Lane Rural Roads. Int. J. Environ. Res. Public Health 2021, 18, 12797. [CrossRef]

19. Šeibokaitè, L.; Markšaitytė, R.; Endriulaitienè, A.; Slavinskienė, J.; Šakinytė, D.; Tamajevaitè, G. Targeting Smartphone Use While Driving: Drivers\&rsquo; Reactions to Different Types of Safety Messages. Sustainability 2021, 13, 13241. [CrossRef]

20. Rogé, J.; Ndiaye, D.; Aillerie, I.; Aillerie, S.; Navarro, J.; Vienne, F. Mechanisms underlying cognitive conspicuity in the detection of cyclists by car drivers. Accid. Anal. Prev. 2017, 104, 88-95. [CrossRef]

21. Lawton, C.A. Gender, spatial abilities, and wayfinding. In Handbook of Gender Research in Psychology; Springer: Berlin/Heidelberg, Germany, 2010; pp. 317-341.

22. Iachini, T.; Sergi, I.; Ruggiero, G.; Gnisci, A. Gender differences in object location memory in a real three-dimensional environment. Brain Cogn. 2005, 59, 52-59. [CrossRef]

23. Matthews, M.H. Gender, Home Range and Environmental Cognition. Trans. Inst. Br. Geogr. 1987, 12, 43-56. [CrossRef]

24. Wijaya, K.T.; Bharoto, L.Y.; Purwanto, A.; Syamsuddin, E.Y. Vision-Based Parking Assist System with Bird-Eye Surround Vision for Reverse Bay Parking Maneuver Recommendation. In Proceedings of the 2020 International Electronics Symposium (IES), Surabaya, Indonesia, 29-30 September 2020; pp. 102-107.

25. Huang, C.-Y. Vehicle Door Opening Control Model Based on a Fuzzy Inference System to Prevent Motorcycle-Vehicle Door Crashes. Sustainability 2021, 13, 12558. [CrossRef] 